Excellence. Guidelines for nutrition support in adults. Clinical Guideline 32. London: NICE, 2006.

3 Elia M, Russell CA, Stratton RJ (eds). Trends in artificial nutrition support in the UK during 1996-2000. Committee of the British Artificial Nutrition Survey, BAPEN, 2001.

4 MacFie J. Enteral versus parenteral nutrition: the significance of bacterial translocation and gut-barrier function. Review. Nutrition 2000;16:606-11.

5 Elia M. Special nutritional problems and the use of enteral and parenteral nutrition. In: Warrell DA, Cox TM, Firth JD (eds). Oxford textbook of medicine, 4th edn. Oxford: Oxford University Press, 2003.

6 Heyland DK, MacDonald S, Keefe L, Drover JW. Total parenteral nutrition in the critically ill patient: a meta-analysis. JAMA 1998;280:2013-9.

7 Elia M. Changing concepts of nutrient requirements in disease: implications for artificial nutritional support. Lancet 1995; 345:1279-84.

8 Stratton RJ, Green CJ, Elia M (eds). Diseaserelated malnutrition: an evidence-based approach to treatment. Wallingford, UK: Cabi Publishing, 2003.

9 Elia M (ed). The 'MUST' report. Nutritional screening for adults: a multidisciplinary responsibility. Development and use of the 'Malnutrition Universal Screening Tool' ('MUST') for adults. A report by the Malnutrition Advisory Group of the British Association for Parenteral and Enteral Nutrition, 2003. www.bapen.org.uk

10 Elia M, Stroud M. Nutrition in acute care. Clin Med 2004;4:405-7.

11 Stroud M, Duncan H, Nightingale J; British Society of Gastroenterology. Guidelines for enteral feeding in adult hospital patients. Gut 2003;52(Suppl 7):viil-vii12.

12 Van den Berghe G, Wouters P, Weekers F et al. Intensive insulin therapy in the critically ill patients. N Engl J Med 2001;345:1359-67.

13 Van den Berghe G, Wilmer A, Hermans G et al. Intensive insulin therapy in the medical ICU. N Engl J Med 2006;354:449-61.

14 Solomon SM, Kirby DF. The refeeding syndrome: a review. J Parenter Enterol Nutr 1990;14:90-7.

\section{The management of upper gastrointestinal}

\section{haemorrhage}

Terence Wong MA MD FRCP, Consultant Gastroenterologist, Department of Gastroenterology, St Thomas' Hospital, London

Clin Med 2006;6:460-4

Upper gastrointestinal haemorrhage (UGIH) is a common medical emergency with an incidence of 50-170 per 100,000 adults per year in the UK. ${ }^{1,2}$ A UK audit found an overall mortality of $14 \%$, with a higher mortality in older patients or those with severe comorbidity. $^{3}$ Mortality has not declined recently because of the increasing age and comorbidity of patients. ${ }^{4}$

\section{Initial assessment}

The initial management of the patient should include a risk assessment of the severity of the bleed and fluid resuscitation (Table 1).

\section{Risk scores in upper gastrointestinal haemorrhage}

Several risk scoring systems have been devised to predict the outcome of UGIH, the commonest of which are the Rockall and Blatchford scores.

Rockall score. This widely used scoring system was based on a prospective national audit of 4,185 cases of UGIH. ${ }^{3}$
The Rockall score, which identifies the risk factors associated with mortality after UGIH, comprises three clinical factors and two endoscopic variables as predictive of mortality (Table 2). The scoring system has been used both preand post-endoscopy. The higher the Rockall score the worse the prognosis; an overall score below three is associated with an excellent prognosis. In this audit, $15 \%$ and $26 \%$ were identified as low risk pre- and post-endoscopy, respectively (Table 3).

Blatchford score. The Blatchford score uses solely clinical and laboratory variables and has no endoscopic component. ${ }^{5}$ In contrast to the Rockall score, the main outcome measurement is the requirement for clinical intervention (blood transfusions, surgical or endoscopic interventions). The score was based on a prospective audit of 1,748 admissions for UGIH in West Scotland

Table 1. Urgent investigations in a haemorrhage.

- Haemoglobin, white cell count, platelet count

- Urea and electrolytes

- Liver function tests

- Blood cross match

- Prothrombin time

- ECG

- Chest X-ray patient with upper gastrointestinal

\section{Key Points}

Risk stratification and resuscitation of patients with upper gastrointestinal haemorrhage are important in the initial management

Advanced age, comorbidity and haemodynamic shock are associated with increased mortality

Endoscopic haemostasis is associated with reduced rebleeding rates and requirement for surgery

KEY WORDS: endoscopy, gastrointestinal haemorrhage, peptic ulcer, proton pump inhibitors, terlipressin, varices 


\begin{tabular}{|c|c|c|c|c|}
\hline \multirow[b]{3}{*}{ Age } & \multicolumn{4}{|c|}{ Score } \\
\hline & 0 & 1 & 2 & 3 \\
\hline & $<60$ years & $60-79$ years & $\geq 80$ years & \\
\hline Shock & $\begin{array}{l}\text { No shock (systolic BP } \\
>100 \mathrm{mmHg} \text {, pulse <100) }\end{array}$ & $\begin{array}{l}\text { Tachycardia alone } \\
\text { (pulse }>100, \\
\text { systolic BP }>100 \mathrm{mmHg} \text { ) }\end{array}$ & $\begin{array}{l}\text { Hypotension } \\
\text { (systolic BP } \\
<100 \mathrm{mmHg} \text { ) }\end{array}$ & \\
\hline Comorbidity & No major comorbidity & & $\begin{array}{l}\text { Cardiac failure, IHD, any } \\
\text { major comorbidity }\end{array}$ & $\begin{array}{l}\text { Renal failure, liver failure, } \\
\text { disseminated malignancy }\end{array}$ \\
\hline Endoscopic diagnosis & $\begin{array}{l}\text { Mallory-Weiss tear, no } \\
\text { lesion identified, no stigmata } \\
\text { of recent haemorrhage }\end{array}$ & All other diagnoses & $\begin{array}{l}\text { Malignancy of upper } \\
\text { Gl tract }\end{array}$ & \\
\hline $\begin{array}{l}\text { Major endoscopic } \\
\text { stigmata of recent } \\
\text { haemorrhage }\end{array}$ & None or dark spot alone & & $\begin{array}{l}\text { Blood in upper Gl tract, } \\
\text { adherent clot, visible or } \\
\text { spurting vessel }\end{array}$ & \\
\hline
\end{tabular}

$\mathrm{BP}=$ blood pressure $; \mathrm{Gl}=$ gastrointestinal; $\mathrm{IHD}=$ ischaemic heart disease .

(Table 4). A simplified 'fast track' score derived from this system (Blatchford score 0 associated with low risk of requiring clinical intervention) identified $99 \%$ of patients who required intervention and $32 \%$ with minor bleeds who did not.

These scoring systems enable patients to be separated into those with low mortality risk and probability of requiring intervention and those with higher mortality risk and high likelihood of intervention. Many units use these scores to identify and triage patients suitable for early discharge, admission into a high dependency area or urgent endoscopy.

\section{Resuscitation}

The immediate management is to resuscitate the patient (a detailed account of this is beyond the scope of this review). ${ }^{6}$ Fluid resuscitation should be commenced. In severe cases of haematemesis an endotracheal tube may be required, especially if the conscious level is impaired (eg in hepatic encephalopathy) to prevent pulmonary aspiration.

\section{Endoscopy}

Endoscopy can be undertaken either as a semi-elective or urgent procedure. The timing has to be taken on an individual case basis but fluid resuscitation takes
Table 3(a). Overall mortality by Rockall score.

$\begin{array}{llllllllll}\text { Rockall score } & 0 & 1 & 2 & 3 & 4 & 5 & 6 & 7 & 8+ \\ \text { Mortality (\%) } & 0 & 0 & 0.2 & 2.9 & 5.3 & 10.8 & 17.3 & 27.0 & 41.1\end{array}$

Table 3(b). Overall mortality by pre-endoscopy risk score.

$\begin{array}{lllllllll}\begin{array}{l}\text { Pre-endoscopy } \\ \text { Rockall score }\end{array} & 0 & 1 & 2 & 3 & 4 & 5 & 6 & 7 \\ \text { Mortality (\%) } & 0.2 & 2.4 & 5.6 & 11.0 & 24.6 & 39.6 & 48.9 & 50.0\end{array}$

Table 4. The Blatchford score.

\begin{tabular}{|c|c|c|}
\hline Admission risk marker & & Score \\
\hline \multirow[t]{5}{*}{ Blood urea (mmol/l) } & $<6.5$ & 0 \\
\hline & $6.5-8.0$ & 2 \\
\hline & $8.0-10$ & 3 \\
\hline & $10-25$ & 4 \\
\hline & $>25$ & 6 \\
\hline \multirow[t]{4}{*}{$\mathrm{Hb}(\mathrm{g} / \mathrm{dl})$ men } & $\geq 13$ & 0 \\
\hline & $12-13$ & 1 \\
\hline & $10-12$ & 3 \\
\hline & $<10$ & 6 \\
\hline \multirow[t]{3}{*}{$\mathrm{Hb}(\mathrm{g} / \mathrm{dl})$ women } & $\geq 12$ & 0 \\
\hline & $10-12$ & 1 \\
\hline & $<10$ & 6 \\
\hline \multirow[t]{4}{*}{ Systolic BP (mmHg) } & $\geq 110$ & 0 \\
\hline & $100-109$ & 1 \\
\hline & 90-99 & 2 \\
\hline & $<90$ & 3 \\
\hline \multirow[t]{5}{*}{ Other markers } & Pulse $\geq 100$ & 1 \\
\hline & Presentation with melaena & 1 \\
\hline & Presentation with syncope & 1 \\
\hline & Hepatic disease & 2 \\
\hline & Cardiac failure & 2 \\
\hline
\end{tabular}

$\mathrm{BP}=$ blood pressure $\mathrm{Hb}=$ haemoglobin. 
priority over endoscopy. Endoscopy should be undertaken when the patient is haemodynamically stable, but this is not always possible in cases of severe bleeding. Ideally, every acute hospital should have arrangements for out-ofhours endoscopy by appropriately trained clinicians, ${ }^{6}$ but there is wide variation in the provision of emergency endoscopy within the UK. A recent National Confidential Enquiry into Patient Outcome and Death reported that $62 \%$ of units had no out-of-hours endoscopy rota.

Endoscopy can define the cause of bleeding (Table 5), aid in risk stratification and enable endoscopic haemostasis to be performed. Specific endoscopic, pharmacological and surgical therapy can then be tailored towards individual causes of bleeding.

\section{Non-variceal upper gastrointestinal haemorrhage}

\section{Endoscopy}

Peptic ulceration. Various endoscopic haemostatic treatments are available to treat peptic ulcers with stigmata of recent haemorrhage (oozing or spurting haemorrhage, visible vessel, adherent clot) including:

- injection therapy (adrenaline, fibrin glue)

- thermal haemostasis (heater probe, argon plasma coagulator), or

- mechanical clips.

Adrenaline injection is associated with an initial haemostasis rate of $95 \%$ and a rebleeding rate of $15-20 \%$. The addition of thermal therapy to adrenaline injec-

Table 5. Causes of upper gastrointestinal haemorrhage.

\begin{tabular}{lc} 
Cause & $\%$ \\
\hline Peptic ulcer & $35-50$ \\
Gastroduodenal \\
erosions/gastritis & $8-15$ \\
Oesophagitis & $5-15$ \\
Oesophageal varices & $5-10$ \\
Mallory-Weiss tear & 15 \\
Malignancy & 4 \\
None identified & $20-25$
\end{tabular}

tions further reduces the rebleeding rate to $5-10 \%$ and also the requirement for surgery. ${ }^{7,8}$

Factors identified as predicting a high risk of rebleeding include shock at presentation, ulcer size above $2 \mathrm{~cm}$, hypotension and haemoglobin less than $10 \mathrm{~g} / \mathrm{dl} .^{9}$ A randomised controlled study (RCT) of endoscopic retreatment against surgery in patients who rebled showed no difference in mortality and a reduced complication rate in those undergoing endoscopic retreatment. ${ }^{10}$ Those with hypotension at the time of rebleed and ulcer size bigger than $2 \mathrm{~cm}$ are more likely to fail endoscopic retreatment and require surgical management of their rebleeding.

Mallory-Weiss tears usually stop bleeding spontaneously. Rarely, adrenaline injections or thermal methods can be used. Other causes of bleeding such as telagiectasias and vascular ectasias can be treated with the argon plasma coagulator.

\section{Pharmacological therapy}

Proton pump inhibitors. The use of proton pump inhibitors (PPIs), potent acid suppressing agents, is based on the observation that $\mathrm{pH}$ over 6 is required for platelet aggregation whereas $\mathrm{pH}$ below 5 results in clot lysis. ${ }^{11}$ In a landmark study from Hong Kong, ${ }^{12} 240$ patients with peptic ulcer bleeding and high-risk stigmata of recent haemorrhage were randomised to receive highdose intravenous (iv) omeprazole (80 mg iv bolus followed by $8 \mathrm{mg}$ per hour for 72 hours) or placebo. Rebleeding occurred in $6.7 \%$ of the high-dose omeprazole group compared with $22.5 \%$ of the placebo arm. On this basis, many units have adopted this protocol in patients who have bled from a peptic ulcer with high-risk stigmata of rebleeding, although this dosage is currently unlicensed.

In contrast, a previous study from the UK found no advantage of iv omeprazole, ${ }^{13}$ possibly because of the inclusion of patients with low-risk peptic ulceration, oesophageal varices and tumours or due to ethnic differences between study populations. A further study suggested a reduction in rebleeding in patients with peptic ulcer haemorrhage who were given oral omeprazole. Endoscopic therapy was not available in this study, so its applicability to routine practice within the UK is uncertain. ${ }^{14}$

\section{Surgical therapy}

Surgery is necessary in patients refractory to initial endotherapy and in patients who rebleed. The on-call upper GI surgical team should be informed of the patient in whom there is the potential for surgical intervention. After a single rebleed the outcomes from endoscopy seem to be equivalent to surgery. ${ }^{10}$ Thereafter, the decision whether to proceed to surgery has to be taken on an individual basis depending on patient age, comorbidity and ulcer size.

Routine repeat endoscopy is not necessary in patients who do not have clinical signs of rebleeding except in the case of gastric ulcer bleeding to exclude malignancy. One study suggested a reduction in rebleeding rates with routine 'secondlook' endoscopy, but this has not been duplicated. ${ }^{15}$ Patients who have bled from peptic ulcers should receive routine ulcer healing therapy including Helicobacter pylori eradication. ${ }^{16}$ In patients who have bled from peptic ulcers due to non-steroidal anti-inflammatory drugs and cannot stop these medications the addition of PPIs reduces the risk of rebleeding, but the risk of recurrent ulceration is still significant. ${ }^{17}$

\section{Variceal haemorrhage}

The mortality from bleeding after a variceal haemorrhage is related to the severity of the liver disease. The ChildPugh score is a commonly used classification to assess the severity of liver disease (Table 6) and is strongly predictive of mortality. ${ }^{18}$

\section{Treatment of acute variceal bleeding}

Endoscopic therapy. The main endoscopic treatment modalities for oesophageal varices are endoscopic variceal band ligation (EVL) and endoscopic variceal sclerotherapy. EVL was first described in 
humans in 1988 and subsequent studies have shown that it is superior to sclerotherapy both in the setting of acute bleeding ${ }^{19}$ and also in secondary prophylaxis of variceal haemorrhage. ${ }^{20}$ The newer multiband variceal banding devices are also superior to the firstgeneration techniques. $^{21}$

Gastric varices are present in approximately $30 \%$ of patients with portal hypertension. They pose a challenge to the endoscopist because of the difficulties in achieving haemostasis with either endoscopic sclerotherapy or band 1 igation. Recent studies using tissue adhesives such as N-butyl-cyanoacylate ${ }^{22}$ and human thrombin ${ }^{23}$ have shown high initial haemostasis rates.

Pharmacological therapy. Terlipressin, vasopressin, somatostatin and octreotide have all been shown to be of some benefit in initial haemostasis and in reducing early rebleeding. Terlipressin reduces mortality; in the UK it is the only licensed vasoactive agent in variceal haemorrhage. ${ }^{24}$ Earlier treatment with vasoactive agents ${ }^{25,26}$ seems to be associated with a better outcome and should therefore be used before endoscopy when a variceal haemorrhage is clinically suspected. The optimal duration of therapy has not been fully established but many studies continued vasoactive drugs for five days. ${ }^{27}$

Prophylactic antibiotics have been shown in multiple meta-analyses to reduce mortality in cirrhotic patients with GI haemorrhage. ${ }^{28}$

Combining endoscopic and pharmacological therapy improves initial haemostasis rates and reduces rebleeding

Table 6. Child-Pugh score.

\begin{tabular}{lccc} 
& \multicolumn{3}{c}{ Score } \\
\hline & 1 & 2 & 3 \\
\hline Encephalopathy & None & Mild & Moderate \\
Ascites & None & Mild-moderate & Severe \\
Bilirubin $(\mu \mathrm{mol} / \mathrm{l})$ & $<34$ & $34-51$ & $>51$ \\
Albumin $(\mathrm{g} / \mathrm{l})$ & $>35$ & $28-35$ & $<28$ \\
INR & $<1.3$ & $1.3-1.5$ & $>1.5$ \\
\hline
\end{tabular}

INR = international normalised ratio. rates compared with endoscopic haemostasis alone. ${ }^{29}$

Balloon tamponade. Balloon tamponade is highly effective in the control of active bleeding but is associated with 50\% rebleeding after deflation of the balloon. It is also associated with risk of oesophageal rupture, ulceration and aspiration pneumonia, but is valuable in torrential bleeding as a temporising manoeuvre whilst awaiting definitive treatment. ${ }^{18,27}$

\section{Transjugular intrahepatic portosystemic} shunt. Transjugular intrahepatic portosystemic shunt (TIPSS) is a procedure in which a self-expanding metal stent is placed radiologically between the portal and hepatic veins. It is highly effective in reducing portal pressures and rebleeding and in controlling acute haemorrhage. ${ }^{18}$ TIPSS is, however, associated with a risk although the latter risk is reduced with the use of the newer polytetrafluoroethylene covered stents. ${ }^{30}$ Its use is currently limited to variceal haemorrhage refractory to endoscopic and pharmacological therapy.

\section{Secondary prophylaxis of variceal haemorrhage}

Beta-blockers. Non-selective beta-blockers reduce cardiac output and cause splanchnic vasoconstriction, reducing portal venous inflow and pressure. Several RCTs comparing popranolol or nadolol with placebo have shown a reduction in rebleeding and mortality with betablockers. ${ }^{18}$ of encephalopathy and shunt stenosis,

Conclusions

Upper gastrointestinal haemorrhage is a life-threatening emergency. Recent advances in therapeutic endoscopy and pharmacological therapy have reduced the rebleeding rate and requirements for surgery. However, risk stratification and resuscitation are as important in the initial management of these patients. Individual units should incorporate these into local protocols for the treatment of patients with upper GI bleeding.

\section{Competing interests}

Dr Wong is an advisor to Boston Scientific Corporation and has received lecture honoraria from Cook Inc.

\section{References}

1 Blatchford O, Davidson LA, Murray WR, Blatchford M, Pell J. Acute upper gastrointestinal haemorrhage in west of Scotland: case ascertainment study. BMJ 1997;315: 510-4.

2 Rockall TA, Logan RF, Devlin HB, Northfield TC. Incidence of and mortality from acute upper gastrointestinal haemorrhage in the United Kingdom. Steering Committee and members of the National Audit of Acute Upper Gastrointestinal Haemorrhage. BMJ 1995;311:222-6.

3 Rockall TA, Logan RF, Devlin HB, Northfield TC. Risk assessment after acute upper gastrointestinal haemorrhage. Gut 1996;38:316-21.

4 Laine L, Peterson WL. Bleeding peptic ulcer. 
N Engl J Med 1994;331:717-27.

5 Blatchford O, Murray WR, Blatchford M. A risk score to predict need for treatment for upper-gastrointestinal haemorrhage. Lancet 2000;356:1318-21.

6 British Society of Gastroenterology Endoscopy Committee. Non-variceal upper gastrointestinal haemorrhage: guidelines. Gut 2002;51(Suppl 4):iv1-6.

7 Chung SS, Lau JY, Sung JJ et al. Randomised comparison between adrenaline injection alone and adrenaline injection plus heat probe treatment for actively bleeding ulcers. BMJ 1997;314:1307-11.

8 Lin HJ, Tseng GY, Perng CL et al. Comparison of adrenaline injection and bipolar electrocoagulation for the arrest of peptic ulcer bleeding. Gut 1999;44:715-9.

9 Wong SK, Yu LM, Lau JY et al. Prediction of therapeutic failure after adrenaline injection plus heater probe treatment in patients with bleeding peptic ulcer. Gut 2002;50:322-5.

10 Lau JY, Sung JJ, Lam YH et al. Endoscopic retreatment compared with surgery in patients with recurrent bleeding after initial endoscopic control of bleeding ulcers. N Engl J Med 1999;340:751-6.

11 Green FW Jr, Kaplan MM, Curtis LE, Levine $\mathrm{PH}$. Effect of acid and pepsin on blood coagulation and platelet aggregation. A possible contributor prolonged gastroduodenal mucosal hemorrhage. Gastroenterology 1978;74:38-43.

12 Lau JY, Sung JJ, Lee KK et al. Effect of intravenous omeprazole on recurrent bleeding after endoscopic treatment of bleeding peptic ulcers. N Engl J Med 2000;343:310-6.

13 Daneshmend TK, Hawkey CJ, Langman M] et al. Omeprazole versus placebo for acute upper gastrointestinal bleeding: randomised double blind controlled trial. BMJ 1992;304:143-7.

14 Khuroo MS, Yattoo GN, Javid G et al. A comparison of omeprazole and placebo for bleeding peptic ulcer. $N$ Engl J Med 1997;336:1054-8.

15 Chiu PW, Lam CY, Lee SW et al. Effect of scheduled second therapeutic endoscopy on peptic ulcer rebleeding: a prospective randomised trial. Gut 2003;52:1403-7.

16 Santander C, Gravalos RG, GomezCedenilla A, Cantero J, Pajares JM. Antimicrobial therapy for Helicobacter pylori infection versus long-term maintenance antisecretion treatment in the prevention of recurrent hemorrhage from peptic ulcer: prospective nonrandomized trial on 125 patients. Am J Gastroenterol 1996;91:1549-52.

17 Chan FK, Hung LC, Suen BY et al. Celecoxib versus diclofenac plus omeprazole in highrisk arthritis patients: results of a randomized double-blind trial. Gastroenterology 2004;127:1038-43.

18 Jalan R, Hayes PC. UK guidelines on the management of variceal haemorrhage in cirrhotic patients. British Society of Gastroenterology. Gut 2000;46(Suppl 3-4): III1-III15.

19 Lo GH, Lai KH, Cheng JS et al. Emergency banding ligation versus sclerotherapy for the control of active bleeding from esophageal varices. Hepatology 1997;25: $1101-4$.

20 Gimson AE, Ramage JK, Panos MZ et al. Randomised trial of variceal banding ligation versus injection sclerotherapy for bleeding oesophageal varies. Lancet 1993; 342:391-4.

21 Wong T, Pereira SP, McNair A, Harrison PM. A prospective, randomized comparison of the ease and safety of variceal ligation using a multiband vs. a conventional ligation device. Endoscopy 2000;32:931-4.

22 Lo GH, Lai KH, Cheng JS, Chen MH, Chiang HT. A prospective, randomized trial of butyl cyanoacrylate injection versus band ligation in the management of bleeding gastric varices. Hepatology 2001;33:1060-4.

23 Heneghan MA, Byrne A, Harrison PM. An open pilot study of the effects of a human fibrin glue for endoscopic treatment of patients with acute bleeding from gastric varices. Gastrointest Endosc 2002;56:422-6.
24 Ioannou G, Doust J, Rockey DC. Terlipressin for acute esophageal variceal hemorrhage. Cochrane Database Syst Rev 2003;(1):CD002147.

25 Levacher S, Letoumelin P, Pateron D et al. Early administration of terlipressin plus glyceryl trinitrate to control active upper gastrointestinal bleeding in cirrhotic patients. Lancet 1995;346:865-8.

26 Nidegger D, Ragot S, Berthelemy P et al. Cirrhosis and bleeding: the need for very early management. J Hepatol 2003;39: 509-14.

27 de Franchis R. Evolving consensus in portal hypertension. Report of the Baveno IV consensus workshop on methodology of diagnosis and therapy in portal hypertension. J Hepatol 2005;43:167-76.

28 Soares-Weiser K, Brezis M, Tur-Kaspa R, Leibovici L. Antibiotic prophylaxis for cirrhotic patients with gastrointestinal bleeding. Cochrane Database Syst Rev 2002;(2):CD002907.

29 Banares R, Albillos A, Rincon D et al Endoscopic treatment versus endoscopic plus pharmacologic treatment for acute variceal bleeding: a meta-analysis. Hepatology 2002;35:609-15.

30 Bureau C, Garcia-Pagan JC, Otal P et al. Improved clinical outcome using polytetrafluoroethylene-coated stents for TIPS: results of a randomized study. Gastroenterology 2004;126:469-75.

31 de la Pena J, Brullet E, Sanchez-Hernandez E et al. Variceal ligation plus nadolol compared with ligation for prophylaxis of variceal rebleeding: a multicenter trial. Hepatology 2005;41:572-8. 